\title{
Relation Between Ring Currents and Hydrogenation Enthalpies for Assessing the Degree of Aromaticity
}

\section{Kumar, Chandan}

2017-09-28

Kumar , C , Fliegl , H \& Sundholm , D 2017 , ' Relation Between Ring Currents and Hydrogenation Enthalpies for Assessing the Degree of Aromaticity ' , Journal of Physical Chemistry A, vol. 121 , no. 38 , pp. 7282-7289 . https://doi.org/10.1021/acs.jpca.7b07607

http://hdl.handle.net/10138/309501

https://doi.org/10.1021/acs.jpca.7b07607

unspecified

acceptedVersion

Downloaded from Helda, University of Helsinki institutional repository.

This is an electronic reprint of the original article.

This reprint may differ from the original in pagination and typographic detail.

Please cite the original version. 


\title{
The Relation Between Ring Currents and
}

\section{Hydrogenation Enthalpies for Assessing the Degree of Aromaticity}

\author{
Chandan Kumar, ${ }^{\dagger}$ Heike Fliegl, ${ }^{*, \dagger}$ and Dage Sundholm*,‡ \\ $\dagger$ Hylleraas Centre for Quantum Molecular Sciences, Department of Chemistry, University \\ of Oslo, P.O.Box 1033, N-1315 Blindern, Norway \\ $\ddagger$ Department of Chemistry, University of Helsinki, P.O. Box 55 (A. I. Virtanens Plats 1), \\ FIN-00014, Finland
}

E-mail: heike.flieg|@kjemi.uio.no; sundholm@chem.helsinki.fi 


\begin{abstract}
Magnetically induced ring-current strength susceptibilities and nucleus independent chemical shifts (NICS) have been studied for 15 single-ring aromatic, antiaromatic and nonaromatic molecules. The current densities have been calculated at the density functional theory (DFT), Hartree-Fock (HF), and second-order Møller-Plesset perturbation theory (MP2) levels using the gauge-including magnetically induced current method (GIMIC). The ring-current strength susceptibilities have been obtained by numerical integration of the current density flowing around the molecular ring. The calculated ring-current strength susceptibilities are almost independent of the level of theory. The relative degree of aromaticity deduced from the magnetic properties has been compared with the ones deduced from hydrogenation enthalpies that are considered to be proportional to aromatic stabilization energies (ASE). For the studied single-ring molecules, GIMIC, NICS and ASE calculations yield similar trends. The study shows that there is a linear correlation between the magnetic and energetic criteria of aromaticity. The largest uncertainty originates from the accuracy of the energy data, because they are much more dependent on the employed computational level than the calculated magnetic properties. Thus, ring-current strength susceptibilities can be used for assessing the degree of aromaticity.
\end{abstract}

\title{
1 Introduction
}

Even though aromaticity is an important concept in chemistry, it is still not understood how to unambiguously determine the degree of aromaticity from electronic structure calculations and therefore it is continuously under debate. ${ }^{1-8}$ Experimentally, aromaticity is known to lead to energy stabilizations, equalizations of bond lengths, preferred substitution reactions, and magnetic properties that differ from those of nonaromatic molecules. ${ }^{9-21}$ Based on calculations, it has been suggested that molecular structures, electron sharing, and bond energies 
belong to the same class of properties as aromaticity implying that the degree of aromaticity can be estimated by using them as indicators. ${ }^{8}$ The magnetic criterion obtained in calculations and experimental proton nuclear magnetic resonance $\left({ }^{1} \mathrm{H}\right.$ NMR $)$ chemical shifts predict concordant degrees of aromaticity. ${ }^{22-27}$

The underlying reason for the aromaticity of organic molecules is electron delocalization in conjugated chemical bonds that form closed two- and three-dimensional electronic pathways sustaining ring currents when the molecule is exposed to an external magnetic field. The closed electron delocalization pathway of aromatic molecules leads to a stabilization of the molecule that influences its molecular structure, dissociation energy and spectroscopic properties. ${ }^{1} \mathrm{H}$ NMR chemical shifts are a particularly important indicator of aromaticity, since the ${ }^{1} \mathrm{H}$ NMR spectra show specific features such as a deshielding and downfield shift for the resonances of the protons that are attached to the exterior part of an aromatic ring. ${ }^{28,29}$ The influence of the aromaticity on the ${ }^{1} \mathrm{H}$ NMR chemical shifts can be explained with the so called ring-current effect, ${ }^{28-30}$ which opens the possibility for assessing the degree of aromaticity by investigating molecular magnetic properties. Calculations of magnetic properties are much simpler than estimating aromatic stabilization energies (ASE) using a series of calculations of homodesmic reaction energies. ${ }^{31-34}$

In the presence of an external magnetic field, aromatic molecules sustain a magnetically induced ring current that generates an induced magnetic field in the opposite direction to the applied one, whereas molecules that strengthen the applied magnetic field are said to be antiaromatic. In aromatic molecules, the electrons circle in the classical (diatropic) direction, whereas antiaromatic molecules are dominated by ring currents in the nonclassical (paratropic) direction. ${ }^{35}$ Magnetically induced current densities have not yet been measured directly, but they are indirectly accessible through measurements of ${ }^{1} \mathrm{H}$ NMR chemical shifts and magnetizabilities. By investigating the pattern of magnetically induced current densities, one can obtain a deeper understanding of aromatic properties and more detailed interpretations of experimental ${ }^{1} \mathrm{H}$ NMR spectra. ${ }^{36-39}$ 
Magnetically induced current densities can be obtained by using quantum chemical calculations. ${ }^{30,35,40-46}$ Integration over the current flow passing selected bonds yields a very reliable aromaticity index as first shown by Sundholm and coworkers, which has later been confirmed by others. ${ }^{41,42,44,45,47-50}$ Magnetic properties such as magnetic susceptibility anisotropy, magnetic susceptibility exaltation, bond magnetizabilities and nucleus independent chemical shifts (NICS) have also been studied in order to estimate the degree of aromaticity according to the magnetic criterion. ${ }^{30,51,52}$

Recently, Frenking et. al. published a study of seven molecules consisting of six-membered rings of which two structures were transition states and concluded that there is no correlation between magnetic and energetic aromaticity criteria. ${ }^{53}$ They recommended the use of the Giambiagi electron delocalization index ${ }^{54}$ that is based on the electron density for determining the degree of aromaticity. ${ }^{53}$ This is somewhat surprising, since a study by Cioslowski et al. showed already ten years ago that the Giambiagi index should be used with caution to assess aromaticity because of its strong sensitivity to the quality of the employed wave function and its inability to distinguish between anti- and nonaromatic systems. ${ }^{55}$ In contrast, the magnetic criterion is rather insensitive to the employed theoretical level as shown in the present work.

The HF trimer was used by Frenking et al. to criticize the magnetic criterion for determining the degree of aromaticity, because $(\mathrm{HF})_{3}$ is a case where NICS calculations fail to predict the correct aromatic character. ${ }^{56}$ However, current density calculations indicate that the NICS approach is unreliable for that system, since integration of the ring-current strength susceptibility shows that $(\mathrm{HF})_{3}$ sustains a very weak ring current and must be considered nonaromatic. ${ }^{57}$ In their article, Frenking et al. did not discuss results obtained by explicit current-density calculations on $(\mathrm{HF})_{3}$. They also concluded that $\mathrm{Sc}_{3}^{-}$based on NICS calculations sustains a paratropic ring current, citing a study by Badri et al. ${ }^{8}$ where $\mathrm{Sc}_{3}^{-}$is not at all discussed. This is somewhat surprising, especially when they present their criticism of the magnetic aromaticity criterion by stating: "triatomic $\mathrm{Sc}_{3}^{-}$that in spite of 
sustaining paramagnetic current is a global minimum on its potential energy surface", which is a statement that has nothing in common with the magnetic aromaticity criterion. In fact, NICS calculations suggest that $\mathrm{Sc}_{3}^{-}$is aromatic, whereas according to current density calculations at the complete active space self-consistent-field (CASSCF) level, $\mathrm{Sc}_{3}^{-}$is practically nonaromatic ${ }^{49}$ showing that explicit integration of ring-current strength susceptibilities is a more reliable approach than NICS values to determine the degree of aromaticity according to the magnetic criterion.

It is a common misconception that NICS and current density calculations are identical approaches by referring to the Biot-Savart relation. A number of studies have shown that current strength susceptibilities obtained from magnetic shielding data depend on the assumed current-pathway model. This is the reason why shielding based approaches results in significant uncertainties in current strength susceptibilities, current pathways, and the degree of aromaticity, in particular when complicated molecules are under consideration. This has been pointed out by several research groups. ${ }^{35,49,58-66}$ Thus, explicit current density calculations are more reliable as compared to NICS values. The calculated current density provides deep insights in particular for complicated ring systems. This is a reason why general conclusions concerning the magnetic aromaticity criterion should not be based on NICS studies only.

In the present work, we investigate whether the magnetic criterion can be used for assessing the degree of aromaticity and whether the magnetic aromaticity criterion is related to the aromatic stabilization energies or not. Mucsi et al. estimated the degree of aromaticity for a number of molecules using hydrogenation enthalpies, which is basically another means to estimate the degree of aromaticity through calculations of aromatic stabilization energies (ASE). ${ }^{67}$ Here, we study the degree of aromaticity for the Mucsi set of 15 selceted molecules consisting of one molecular ring. The degree of aromaticity has been estimated by calculating and analyzing the magnetically induced current density and nucleus independent chemical shifts. The results are compared to the degree of aromaticity calculated by Mucsi et al. using 
hydrogenation enthalpies. ${ }^{67}$

The paper is organized in the following manner. We present the computational details in section 2. In section 3, the calculated ring-current strength susceptibilies and NICS values are discussed and the relative aromaticities are compared with the ones deduced from ASE energies. The final conclusions are drawn in section 4.

\section{Computational details}

The molecular structures were optimized at the density functional theory (DFT) level employing Becke's three-parameter functional in combination with the Lee-Yang-Parr correlation functional (B3LYP). ${ }^{68,69}$ We used the Gaussian 09 program $^{70}$ and the $6-31 \mathrm{G}(\mathrm{d})$ basis set $^{71}$ in the structure optimization in order to obtain the same molecular structures as used in Ref. 67. Vibrational frequencies were calculated to ensure that the obtained molecular structures are minima on the potential energy surfaces.

The studied molecules shown in Figure 1 are benzene $\mathrm{C}_{6} \mathrm{H}_{6}(\mathbf{1})$, cyclobutadiene $\mathrm{C}_{4} \mathrm{H}_{4}(\mathbf{2})$, cyclohexadiene $\mathrm{C}_{6} \mathrm{H}_{8}(\mathbf{3})$, pyridine $\mathrm{C}_{5} \mathrm{H}_{5} \mathrm{~N}(\mathbf{8})$, pyrimidine $\mathrm{C}_{4} \mathrm{H}_{4} \mathrm{~N}_{2}(\mathbf{9})$, furan $\mathrm{C}_{4} \mathrm{H}_{4} \mathrm{O}(\mathbf{1 0})$, pyrrole $\mathrm{C}_{4} \mathrm{H}_{5} \mathrm{~N}(\mathbf{1 1})$, thiophene $\mathrm{C}_{4} \mathrm{H}_{4} \mathrm{~S}(\mathbf{1 2})$, phosphole $\mathrm{C}_{4} \mathrm{H}_{5} \mathrm{P}(\mathbf{1 3})$, azete $\mathrm{C}_{3} \mathrm{H}_{3} \mathrm{~N}(\mathbf{1 8})$, 3methylene-2-oxiranone $\mathrm{C}_{3} \mathrm{H}_{2} \mathrm{O}_{2}(\mathbf{1 9})$, 1H-acet-2-one $\mathrm{C}_{3} \mathrm{H}_{3} \mathrm{NO}(\mathbf{2 0})$, 2H-thiet-2-one $\mathrm{C}_{3} \mathrm{H}_{2} \mathrm{OS}$ (21), 1H-phosphet-2-one $\mathrm{C}_{3} \mathrm{H}_{3} \mathrm{OP}(\mathbf{2 2})$, and cyclooctatriene $\mathrm{C}_{8} \mathrm{H}_{10}$ (26). The molecular structures are visualized using VMD. ${ }^{72}$ We use the same numbering of the molecules as introduced by Mucsi et al. ${ }^{67}$

Nuclear magnetic shieldings were calculated for the optimized structures at the B3LYP level using the def2-TZVP basis sets. ${ }^{73,74}$ The magnetic shieldings were calculated with Turbomole. ${ }^{75-77}$ The magnetic shieldings were also calculated at the Hartree-Fock (HF) and second-order Møller-Plesset perturbation theory (MP2) level using Turbomole. ${ }^{75,78,79}$ Magnetically induced current density susceptibilities were calculated at the same levels of theory with the GIMIC program. ${ }^{41}$ GIMIC is an open-source program that uses the one- 
electron density matrix and the magnetically perturbed one-electron matrices as well as basis-set information as input data. ${ }^{41,43-45}$ GIMIC is a free software that is available online. ${ }^{80}$ Current densities can also be calculated using other softwares. ${ }^{81-87}$

Ring-current strength susceptibilities were obtained by integrating the current density susceptibility that passes a plane perpendicularly to the molecular ring. All electrons were considered in the current-density calculations. The integration domain starts in the middle of the ring and extends 5 bohr outside the molecule. The integration plane extends 5 bohr above and below the molecular ring.

The relative degree of aromaticity was obtained by using benzene and cyclobutadiene as reference molecules for typical aromatic and antiaromatic compounds, respectively. The obtained ring-current strength susceptibilities for benzene and cyclobutadiene at the B3LYP/def2-TZVP level are $11.99 \mathrm{nAT}^{-1}$ and $-19.91 \mathrm{nAT}^{-1}$, respectively, which we here assign to $100 \%$ aromaticity and $-100 \%$ aromaticity (100\% anti-aromaticity), respectively. The corresponding MP2 values are 12.32 (13.03) nAT ${ }^{-1}$ and $-19.68(-20.53) \mathrm{nAT}^{-1}$ with the HF values given in parenthesis.

NICS values were calculated for comparison at the B3LYP/def2-TZVP level, ${ }^{52,88}$ even though NICS values have been questioned as aromaticity index by a large number of researchers. ${ }^{35,36,49,58-66,89} \mathrm{NICS}(0)$ values are the negative isotropic shielding constant calculated in the center of the molecular ring and NICS(1) values are calculated $1 \AA$ above the ring plane. The $\operatorname{NICS}_{z z}(0)$ and $\operatorname{NICS}_{z z}(1)$ values are obtained analogously by using the $z z$

component of the nuclear magnetic shielding tensor in the ring center and $1 \AA$ above it, respectively.

\section{Results}

The ring-current strength susceptibilities and NICS values calculated at the B3LYP level are summarized in Table 1 and Table 2. In Table 1, the degree of aromaticity (in \%) rela- 
tive to benzene and cyclobutadiene obtained from the ring-current strength susceptibility is compared to the aromaticity scale based on enthalpies of hydrogenation reactions calculated by Mucsi et al. ${ }^{67}$ They found that the degree of aromaticity deduced from the hydrogenation enthalpies are strongly basis-set dependent with up to $20 \%$ changes in both directions when increasing the basis-set size from $6-31 \mathrm{G}(\mathrm{d})$ to $6-311++\mathrm{G}(2 \mathrm{~d}, 2 \mathrm{p}) .{ }^{67}$ Current densities do not depend much on the basis-set quality when gauge-including atomic orbitals (GIAO) are employed. ${ }^{90}$

The current-density calculations at the DFT, HF and MP2 levels also show that practically the same ring-current strength susceptibilities are obtained for the studied molecules at these levels of theory. The linear regression coefficients for the fit of the ring-current strength susceptibilities calculated at the B3LYP and HF levels are $a=0.991$ and $b=-0.433 \mathrm{nAT}^{-1}$ with an $R^{2}$ value of 0.994 . $a$ is the slope and $b$ is the intercept. The corresponding coefficients for the linear fit of the B3LYP and MP2 data are $a=0.968$ and $b=-0.288 \mathrm{nAT}^{-1}$ with an $R^{2}$ value of 0.999 . The corresponding coefficients for the linear fit of the MP2 and HF data are $a=1.023$ and $b=-0.147 \mathrm{nAT}^{-1}$ with an $R^{2}$ value of 0.993 . The plots of the fits are given as supporting information.

The ring-current strength susceptibility as well as all NICS flavors used in this study suggest that pyrrole is more aromatic than thiophene, which was also obtained in the ASE calculations and experimentally. ${ }^{67}$ The same conclusion was drawn in a previous study. ${ }^{52}$ In contrast, the Giambiagi index suggests that thiophene is more aromatic than pyrrole, ${ }^{55}$ which agrees with the results of a recent shielding based study. ${ }^{91}$ Thus, the aromaticity order of pyrrole and thiophene is not settled. However, in contrast to the Giambiagi index the calculated ring-current strength susceptibilities are not sensitive to the level of electron correlation treatment, since HF, MP2 and DFT calculations yield almost the same ringcurrent strength susceptibilities.

A comparison of the relative degree of aromaticity (in \%) obtained from ring-current strength susceptibilities calculated at the B3LYP level and hydrogenation enthalpies taken 
from Ref. 67 is given in Figure 2. The black dashed line indicates the perfect agreement, whereas the red line is a linear regression fit to the calculated data. The individual data points for each molecule are shown in red. The slope of the fitted curve is 1.035 , which is very close to the ideal one of 1 . The intercept is $14.6 \%$. The correlation coefficient $R^{2}$ is 0.945. At the MP2 level, we obtained a slope of 1.060 and an intercept of $15.7 \%$ with an $R^{2}$ value of 0.939 for the fit. At the HF level, the corresponding data are $0.990,14.7 \%$, and 0.957 .

Thus, the relative degree of aromaticity based on the ring-current strength susceptibility and on the aromatic stabilization energies agrees well. There is a clear correlation between the aromaticity indices of ring-current strength susceptibility and the energetic criterion. The largest uncertainty originates from the calculated enthalpies, which depend on the employed basis sets and level of theory. Ring-current strength susceptibilities are in general not sensitive to the employed computational level. ${ }^{41}$

Comparisons of the relative degrees of aromaticity (in \%) obtained from NICS calculations and calculated hydrogenation enthalpies are shown in Figure 3. The correlation coefficients $R^{2}$ for $\operatorname{NICS}(1), \operatorname{NICS}(1)_{z z}, \operatorname{NICS}(0)$ and $\operatorname{NICS}(0)_{z z}$ are $0.937,0.927,0.776$ and 0.962 , respectively. Thus, $\operatorname{NICS}(0)_{z z}$ performs best for the studied molecules, whereas the $\operatorname{NICS}(0)$ values has the worst correlation with energy data. The $\operatorname{NICS}(1)_{z z}$ index is generally considered as the best choice when contributions from all electrons are taken into account. ${ }^{21}$ In the present NICS fits, the angular coefficients of 1.023, 1.043, 1.164, and 1.050 are very close to the perfect fit value of 1 . In the corresponding study of Fallah-Bagher-Shaidaei et al., the relation between ASE and NICS values were $-1.730,-0.604,-1.213$, and $-0.506 \mathrm{kcal}$ $\mathrm{mol}^{-1} \mathrm{ppm}^{-1}$ for $\operatorname{NICS}(1), \operatorname{NICS}(1)_{z z}, \operatorname{NICS}(0)$ and $\operatorname{NICS}(0)_{z z}$ calculations, respectively. ${ }^{21}$ They did not report any relative degree of aromaticity that could be directly compared with the present results. 


\section{Summary and conclusions}

Magnetically induced current density susceptibilities and nucleus independent chemical shifts have been calculated for 15 single-ring aromatic, antiaromatic and nonaromatic molecules containing heteroatoms. The relative degree of aromaticity deduced from the magnetic properties has been compared with the relative aromaticity deduced from hydrogenation enthalpies reported by Mucsi et. al. ${ }^{67}$ The hydrogenation enthalpies are considered to be proportional to aromatic stabilization energies (ASE).

The integrated ring-current strength susceptibilities have been calculated using the gauge including magnetically induced currents (GIMIC) approach. ${ }^{41,45}$ The nucleus independent chemical shifts (NICS) values are the negative magnetic shieldings calculated in selected points. ${ }^{52}$ The aromatic scales have been obtained by setting the ring-current strength susceptibilities and NICS values for benzene and cyclobutadiene to $100 \%$ and $-100 \%$, respectively. Thus, benzene and cyclobutadiene are assumed to be the archetypical aromatic and antiaromatic molecules. Linear regression shows that there is a clear correlation between the relative aromaticities obtained using the energetic and magnetic criteria. For the studied single-ring molecules, the fits of the GIMIC, NICS(1), NICS(1) $z z, \operatorname{NICS}(0)_{z z}$ data yield roughly concordant results. The NICS(0) index is less reliable that the other ones employed in this work. The largest uncertainty is due to the accuracy of the employed energy data, because enthalpies are much more dependent on the employed computational level and basis set than the calculated magnetic properties. Ring-current strength susceptibility calculations at B3LYP, HF and MP2 levels of theory yield qualitatively the same degree of aromaticity. Figure 4 shows an overview of the relative deviations of the GIMIC and NICS methods with respect to the hydrogenation energies.

The general applicability of the magnetic criterion for assessing the degree of aromaticity has been questioned in a recent study by Frenking et. al. ${ }^{53}$ Instead of adopting the magnetic criterion Frenking and co-workers recommended to use the Giambiagi index ${ }^{54}$ as a more reliable means for assessing the degree of aromaticity. However, it is known that the Giambiagi 
index should be applied with caution to assess aromaticity because of its strong sensitivity to the quality of the employed wave function and its inability to distinguish between antiand nonaromatic systems, ${ }^{55}$ which is not the case for ring-current strength susceptibilities.

It is important to stress that Frenking et al. ${ }^{53}$ studied only 7 molecules of which 2 (1a and $2 \mathrm{a}$ in their paper) are higher-order transition states. The only molecules of relevance were $1 \mathrm{~b}, 1 \mathrm{c}, 2 \mathrm{~b}$ and $2 \mathrm{c}$, since benzene was the reference molecule. Molecule $2 \mathrm{~b}$ is $10 \mathrm{~kJ} / \mathrm{mol}$ below $2 \mathrm{c}$ and $1 \mathrm{~b}$ is $0.4 \mathrm{~kJ} / \mathrm{mol}$ below 1c. They reported current strengths of $7.6 \mathrm{nA} / \mathrm{T}$ and $6.9 \mathrm{nA} / \mathrm{T}$ for $1 \mathrm{~b}$ and $1 \mathrm{c}$ and $4.4 \mathrm{nA} / \mathrm{T}$ and $3.9 \mathrm{nA} / \mathrm{T}$ for $2 \mathrm{~b}$ and $2 \mathrm{c}$. The molecules with stronger current are lower in energy as expected from this work, whereas Frenking et al. did not find any correlation. Thus, it is hard to consider their conclusions of general relevance. In contrast, Fallah-Bagher-Shaidaei et $a l .{ }^{21}$ studied 75 molecules and found a correlation between the aromatic stabilization energy (ASE) and NICS. We have studied 15 further molecules and reached the same conclusion. The main limitation is the accuracy of the ASE data. ${ }^{34,67}$

Our study shows that for the single-ring molecules, NICS and GIMIC yield similar trends. $\mathrm{NICS}_{z z}(0)$ is found to have the best correlation with energy data. However, for molecules consisting of several rings, the adjacent rings affects the current pathways and the induced magnetic field, rendering assessments of the degree of aromaticity using NICS values difficult. ${ }^{36,37,92}$ In particular for weakly aromatic or for almost non-aromatic rings, NICS might lead to incorrect conclusions about molecular aromaticity, ${ }^{57}$ because other currents than ring currents contribute to the magnetic shielding in selected points leading to NICS values that significantly differ from zero even though the molecule does not sustain any significant ring current as seen for example for the $(\mathrm{HF})_{3}$ trimer. ${ }^{56,57}$ The present study shows that for common single-ring molecules, current-density and NICS calculations indeed yield the same relative aromaticity as the calculations of hydrogenation enthalpies. We obtained a linear correlation between the relative degree of aromaticity based on the magnetic and energetic criteria. 
The aromatic character deduced from ring-current strength susceptibilities suggests that pyrrole is more aromatic than thiophene and furan, whereas the Giambiagi index suggests a different order. ${ }^{55}$ The present study shows that there is clear evidence for a linear correlation between the aromatic stabilization energy and magnetic aromaticity indicators such as ringcurrent strength susceptibilities. Thus, the criticism of the magnetic aromaticity criterion by Frenking et al. is not very well founded. ${ }^{53}$

Calculations of ring-current susceptibilities yield a very useful aromaticity index, because it is not sensitive to the employed level of theory and it can also be used in aromaticity studies of general molecules consisting of complex multiring structures. ${ }^{93-102}$

\section{Acknowledgment}

The Norwegian Research Council has supported this work through the CoE Centre for Theoretical and Computational Chemistry (Grant No. 179568/V30 and 231571/F20). The Academy of Finland has also supported this work through project 275845 . We acknowledge computational resources from the Norwegian Supercomputing Program (NOTUR) grant No. NN4654K and from CSC - IT Center for Science, Finland. 
Table 1: The ring-current strength susceptibility I (in $\mathrm{nAT}^{-1}$ ) calculated at B3LYP/def2-TZVP level and the relative aromatic character (GIMIC in \%) based on the calculated ring-current strength susceptibilities are compared with the relative aromatic character deduced from the $z z$ component of the nucleus independent chemical shift calculated $1 \AA$ above the ring and from the hydrogenation energies $\left(\Delta \Delta \mathrm{H}_{\mathrm{H}_{2}}\right)$ calculated at the B3LYP/6-311++G $(2 \mathrm{~d}, 2 \mathrm{p})$ level of theory. The $\Delta \Delta \mathrm{H}_{\mathrm{H}_{2}}$ values are taken from Ref. 67 . Benzene and cyclobutadiene are used as reference aromatic and antiaromatic molecules.

\begin{tabular}{lccccc}
\hline \hline Molecule & Number & $\mathrm{I}$ & GIMIC $\%$ & NICS $_{z z}(1) \%$ & $\Delta \Delta \mathrm{H}_{\mathrm{H}_{2}} \%$ \\
\hline $\mathrm{C}_{6} \mathrm{H}_{6}$ & 1 & 11.99 & 100 & 100 & 100 \\
$\mathrm{C}_{4} \mathrm{H}_{4}$ & 2 & -19.91 & -100 & -100 & -100 \\
$\mathrm{C}_{6} \mathrm{H}_{8}$ & 3 & -0.39 & -1.95 & -7.4 & 2.35 \\
$\mathrm{C}_{5} \mathrm{H}_{5} \mathrm{~N}$ & 8 & 11.47 & 95.66 & 97.9 & 97.25 \\
$\mathrm{C}_{4} \mathrm{H}_{4} \mathrm{~N}_{2}$ & 9 & 10.62 & 88.57 & 93.8 & 76.45 \\
$\mathrm{C}_{4} \mathrm{H}_{4} \mathrm{O}$ & 10 & 10.21 & 85.15 & 94.3 & 57.42 \\
$\mathrm{C}_{4} \mathrm{H}_{5} \mathrm{~N}$ & 11 & 11.67 & 97.33 & 107.1 & 64.53 \\
$\mathrm{C}_{4} \mathrm{H}_{4} \mathrm{~S}$ & 12 & 11.41 & 95.16 & 98.1 & 51.94 \\
$\mathrm{C}_{4} \mathrm{H}_{5} \mathrm{P}$ & 13 & 6.59 & 54.96 & 52.6 & 14.38 \\
$\mathrm{C}_{3} \mathrm{H}_{3} \mathrm{~N}$ & 18 & -18.43 & -92.56 & -87.5 & -103.20 \\
$\mathrm{C}_{3} \mathrm{H}_{2} \mathrm{O}$ & 19 & -3.31 & -16.62 & -15.2 & -36.03 \\
$\mathrm{C}_{3} \mathrm{H}_{3} \mathrm{NO}$ & 20 & -3.00 & -15.06 & -13.5 & -43.49 \\
$\mathrm{C}_{3} \mathrm{H}_{2} \mathrm{OS}$ & 21 & -5.50 & -27.62 & -27.4 & -27.71 \\
$\mathrm{C}_{3} \mathrm{H}_{3} \mathrm{OP}$ & 22 & -1.71 & -8.58 & -11.2 & -9.39 \\
$\mathrm{C}_{8} \mathrm{H}_{10}$ & 26 & 2.59 & 21.6 & -0.14 & 7.38 \\
\hline \hline
\end{tabular}


Table 2: Calculated B3LYP/def2-TZVP nucleus independent chemical shifts (NICS) values in ppm.

\begin{tabular}{lccccc}
\hline \hline Molecule & Number & NICS $(1)_{z z}$ & NICS $(0)_{z z}$ & NICS $(1)$ & NICS(0) \\
\hline $\mathrm{C}_{6} \mathrm{H}_{6}$ & 1 & -29.60 & -16.05 & -9.99 & -8.12 \\
$\mathrm{C}_{4} \mathrm{H}_{4}$ & 2 & 55.81 & 112.27 & 17.46 & 27.40 \\
$\mathrm{C}_{6} \mathrm{H}_{8}$ & 3 & 4.14 & 24.14 & 0.07 & -2.60 \\
$\mathrm{C}_{5} \mathrm{H}_{5} \mathrm{~N}$ & 8 & -28.97 & -14.80 & -9.95 & -6.78 \\
$\mathrm{C}_{4} \mathrm{H}_{4} \mathrm{~N}_{2}$ & 9 & -27.77 & -12.62 & -9.70 & -5.47 \\
$\mathrm{C}_{4} \mathrm{H}_{4} \mathrm{O}$ & 10 & -27.91 & -10.29 & -9.34 & -11.78 \\
$\mathrm{C}_{4} \mathrm{H}_{5} \mathrm{~N}$ & 11 & -31.71 & -14.11 & -10.25 & -13.77 \\
$\mathrm{C}_{4} \mathrm{H}_{4} \mathrm{~S}$ & 12 & -29.04 & -11.28 & -10.19 & -12.90 \\
$\mathrm{C}_{4} \mathrm{H}_{5} \mathrm{P}$ & 13 & -15.58 & 4.33 & -5.55 & -5.44 \\
$\mathrm{C}_{3} \mathrm{H}_{3} \mathrm{~N}$ & 18 & 48.84 & 114.62 & 14.38 & 29.07 \\
$\mathrm{C}_{3} \mathrm{H}_{2} \mathrm{O}_{2}$ & 19 & 8.46 & 44.39 & 1.23 & 1.56 \\
$\mathrm{C}_{3} \mathrm{H}_{3} \mathrm{NO}$ & 20 & 7.52 & 43.31 & 1.14 & 4.14 \\
$\mathrm{C}_{3} \mathrm{H}_{2} \mathrm{OS}$ & 21 & 15.31 & 48.15 & 3.04 & 3.83 \\
$\mathrm{C}_{3} \mathrm{H}_{3} \mathrm{OP}$ & 22 & 6.18 & 35.91 & 0.15 & 6.76 \\
$\mathrm{C}_{8} \mathrm{H}_{10}$ & 26 & 0.08 & 5.94 & -2.40 & -1.13 \\
\hline \hline
\end{tabular}

Table 3: The ring-current strength susceptibility I (in $\mathrm{nAT}^{-1}$ ) calculated at Hartree-Fock (HF) and second-order Møller-Plesset perturbation theory (MP2) level. The relative aromatic character (GIMIC in \%) based on the calculated ring-current strength susceptibilities are also given.

\begin{tabular}{lccccc}
\hline \hline Molecule & Number & $\mathrm{I}(\mathrm{HF})$ & $\%$ & $\mathrm{I}(\mathrm{MP} 2)$ & $\%$ \\
\hline $\mathrm{C}_{6} \mathrm{H}_{6}$ & 1 & 13.03 & 100 & 12.32 & 100 \\
$\mathrm{C}_{4} \mathrm{H}_{4}$ & 2 & -20.53 & -100 & -19.68 & -100 \\
$\mathrm{C}_{6} \mathrm{H}_{8}$ & 3 & -0.21 & -1.02 & -0.39 & -1.98 \\
$\mathrm{C}_{5} \mathrm{H}_{5} \mathrm{~N}$ & 8 & 12.46 & 95.62 & 11.97 & 97.15 \\
$\mathrm{C}_{4} \mathrm{H}_{4} \mathrm{~N}_{2}$ & 9 & 11.29 & 86.64 & 11.42 & 92.69 \\
$\mathrm{C}_{4} \mathrm{H}_{4} \mathrm{O}$ & 10 & 9.95 & 76.36 & 11.05 & 89.69 \\
$\mathrm{C}_{4} \mathrm{H}_{5} \mathrm{~N}$ & 11 & 12.16 & 93.32 & 12.52 & 101.62 \\
$\mathrm{C}_{4} \mathrm{H}_{4} \mathrm{~S}$ & 12 & 11.36 & 87.18 & 12.33 & 100.08 \\
$\mathrm{C}_{4} \mathrm{H}_{5} \mathrm{P}$ & 13 & 5.82 & 44.66 & 7.19 & 58.36 \\
$\mathrm{C}_{3} \mathrm{H}_{3} \mathrm{~N}$ & 18 & -18.21 & -88.69 & -19.29 & -98.01 \\
$\mathrm{C}_{3} \mathrm{H}_{2} \mathrm{O}_{2}$ & 19 & -2.06 & -10.03 & -3.11 & -15.80 \\
$\mathrm{C}_{3} \mathrm{H}_{3} \mathrm{NO}$ & 20 & -1.89 & -9.20 & -2.57 & -13.05 \\
$\mathrm{C}_{3} \mathrm{H}_{2} \mathrm{OS}$ & 21 & -3.51 & -17.09 & -5.15 & -26.16 \\
$\mathrm{C}_{3} \mathrm{H}_{3} \mathrm{OP}$ & 22 & -0.92 & -4.48 & -1.70 & -8.63 \\
$\mathrm{C}_{8} \mathrm{H}_{10}$ & 26 & 2.32 & 17.80 & 2.66 & 21.59 \\
\hline \hline
\end{tabular}




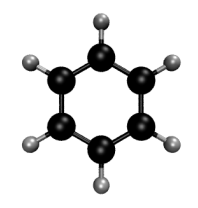

(a) (1)

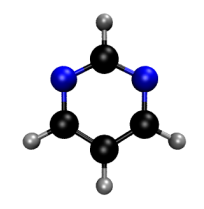

(e) $(\mathbf{9})$

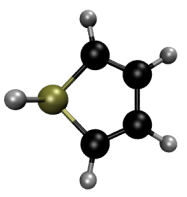

(i) $(\mathbf{1 3})$

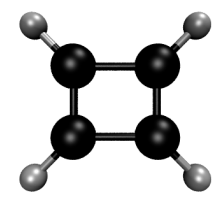

(b) (2)

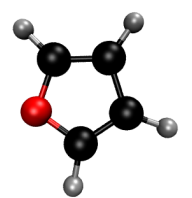

(f) (10)

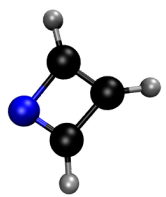

(j) $(18)$

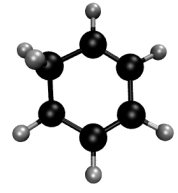

(c) $(3)$

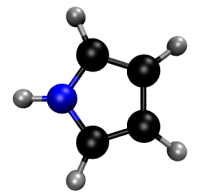

(g) $(\mathbf{1 1})$

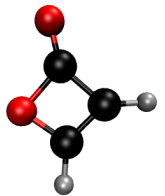

(k) (19)

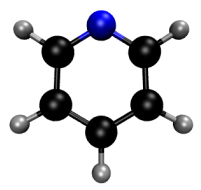

(d) $(8)$

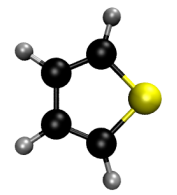

(h) (12)

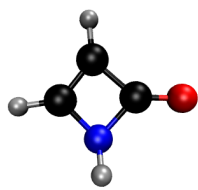

(1) (20)

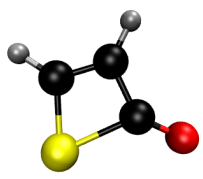

(m) $(\mathbf{2 1})$

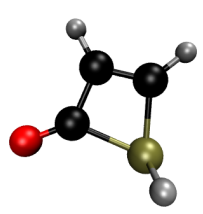

(n) $(\mathbf{2 2})$

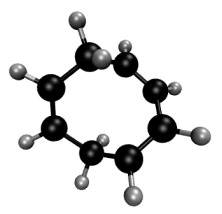

(о) $(\mathbf{2 6})$

Figure 1: Overview of investigated molecular structures. (1) benzene $\mathrm{C}_{6} \mathrm{H}_{6}$, (2) cyclobutadiene $\mathrm{C}_{4} \mathrm{H}_{4}$, (3) cyclohexadiene $\mathrm{C}_{6} \mathrm{H}_{8}$, (8) pyridine $\mathrm{C}_{5} \mathrm{H}_{5} \mathrm{~N}$, (9) pyrimidine $\mathrm{C}_{4} \mathrm{H}_{4} \mathrm{~N}_{2}$, (10) furan $\mathrm{C}_{4} \mathrm{H}_{4} \mathrm{O}$, (11) pyrrole $\mathrm{C}_{4} \mathrm{H}_{5} \mathrm{~N}$, (12) thiophene $\mathrm{C}_{4} \mathrm{H}_{4} \mathrm{~S}$, (13) phosphole $\mathrm{C}_{4} \mathrm{H}_{5} \mathrm{P}$, (18) azete $\mathrm{C}_{3} \mathrm{H}_{3} \mathrm{~N}$, (19) 3-methylene-2-oxiranone $\mathrm{C}_{3} \mathrm{H}_{2} \mathrm{O}_{2}$, (20) $1 \mathrm{H}$-azete-2-one $\mathrm{C}_{3} \mathrm{H}_{3} \mathrm{NO}$, (21) 2H-thiet-2-one $\mathrm{C}_{3} \mathrm{H}_{2} \mathrm{OS},(22) 1 \mathrm{H}$-phosphet-2-one $\mathrm{C}_{3} \mathrm{H}_{3} \mathrm{OP}$, and (26) cyclooctatriene $\mathrm{C}_{8} \mathrm{H}_{10}$. The numbering of the molecules is the same as employed in Ref. 67 . 


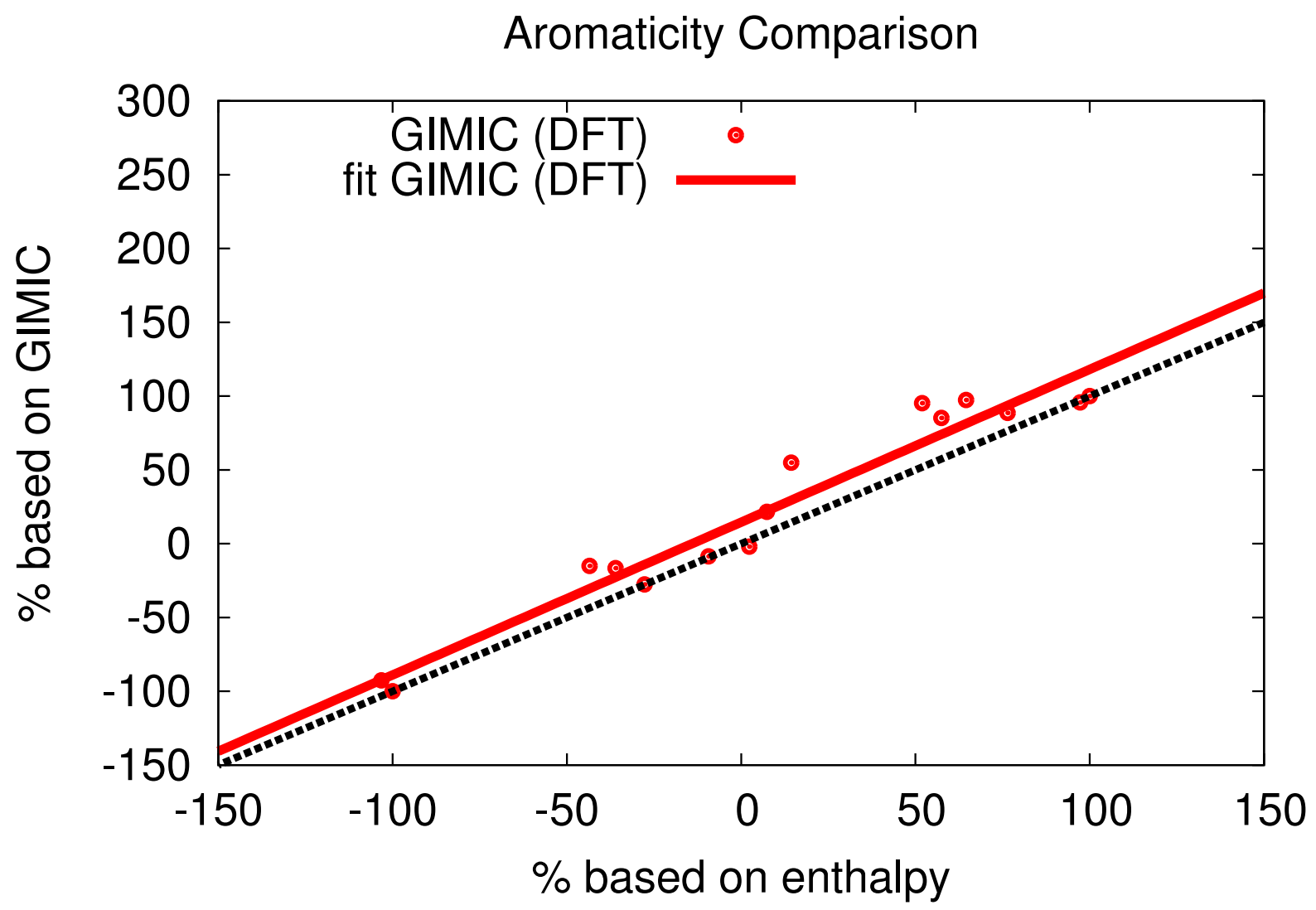

Figure 2: The linear regression fit of $\%$ of aromaticity based on GIMIC calculations at the DFT level. The fitting coefficients of $Y=a X+b$ are $a=1.035$ and $b=14.584 \%$. The $R^{2}$ value for the correlations is 0.945 . Perfect correlation is indicated with the dashed line. Errors in the coefficients are reported as supporting information. 


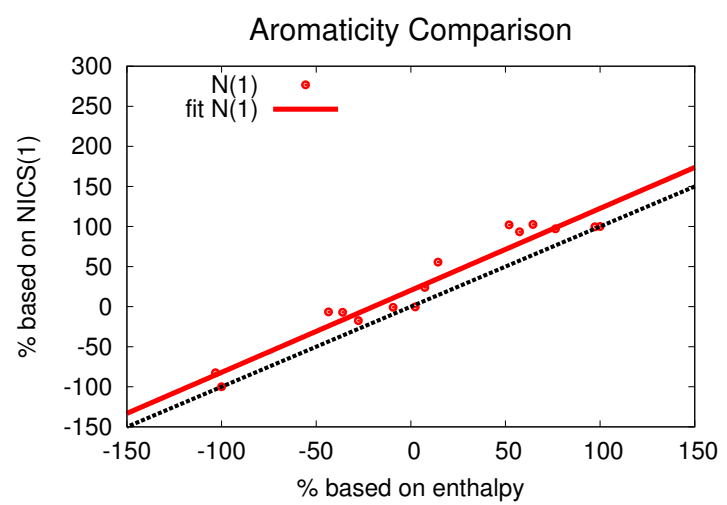

(a)

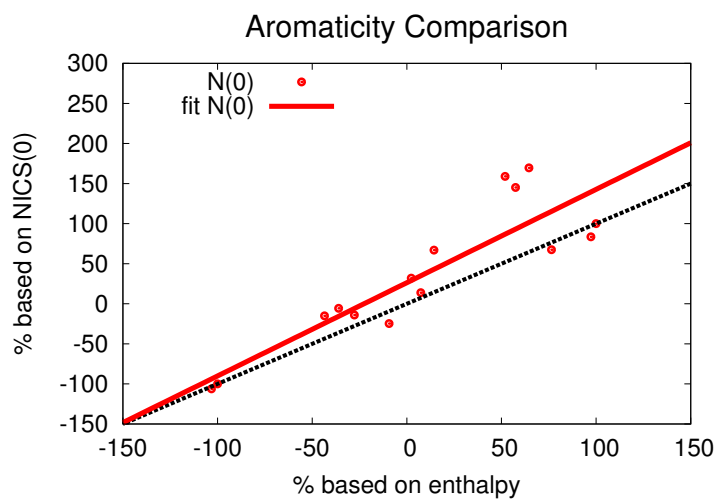

(c)

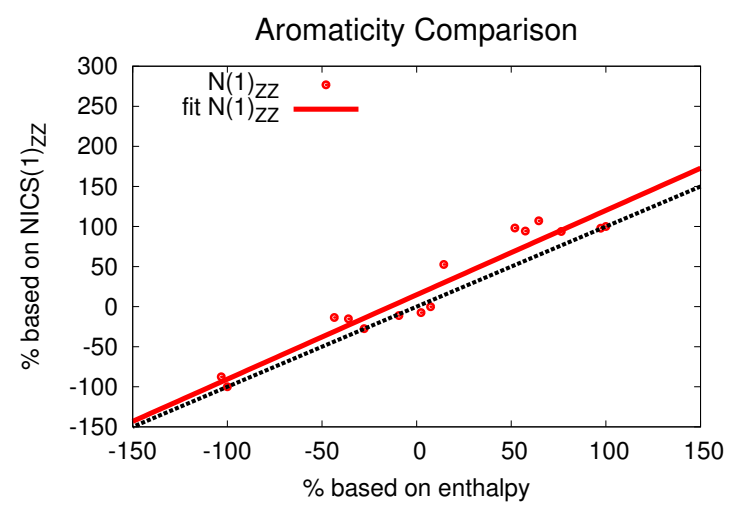

(b)

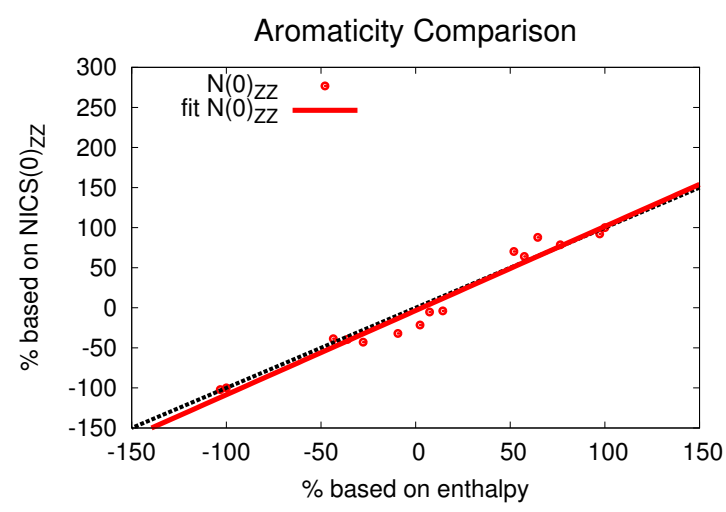

(d)

Figure 3: The linear regression fits for the NICS calculations at the DFT level. The fitting coefficients of $Y=a x+b$ are $a=1.023, b=20.294 \%, R^{2}=0.937$ for (a), $a=1.053$, $b=14.792 \%, R^{2}=0.927$ for (b), $a=1.164, b=26.326 \%, R^{2}=0.776$ for (c), and $a=1.050$, $b=-3.486 \%, R^{2}=0.962$ for (d). Perfect correlation is indicated with the dashed lines. Errors in the coefficients are reported as supporting information. 


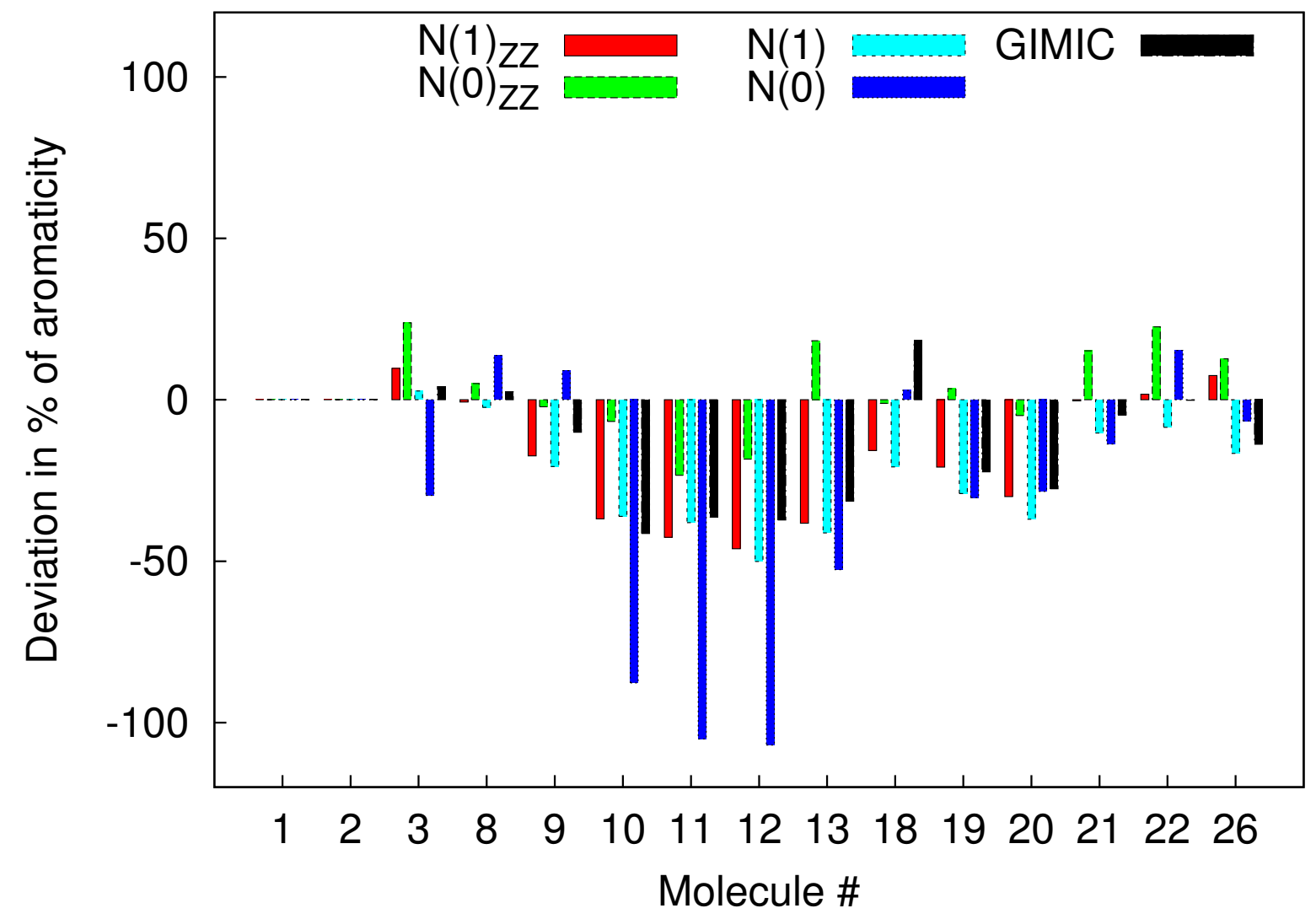

Figure 4: Overview of the deviations of the different methods as compared to the $\%$ of aromaticity based on the enthalpy, which has been taken as reference value. The present calculations have been performed at the B3LYP/def2-TZVP level.

\section{References}

(1) Solá, M. Why Aromaticity Is a Suspicious Concept? Why? Front. Chem. 2017, 5, 22.

(2) Hoffmann, R. The Many Guises of Aromaticity: Is hype debasing a core chemical concept? American Scientist 2015, 103, 18-22.

(3) Ritter, S. K. Aromaticity For All. Chem. Eng. News 2015, 93, 37-38.

(4) Balaban, A. T.; von Ragué Schleyer, P.; Rzepa, H. S. Crocker, Not Armit and Robinson, Begat the Six Aromatic Electrons. Chem. Rev. 2005, 105, 3436-3447. 
(5) Balaban, A. T. Is aromaticity outmoded? Pure Appl. Chem. 1980, 52, 1409-1429.

(6) Frenking, G.; Krapp, A. Unicorns in the world of chemical bonding models. J. Comp. Chem. 2007, 28, 15-24.

(7) Lloyd, D. What Is Aromaticity? J. Chem. Inf. Comput. Sci. 1996, 36, 442-447.

(8) Badri, Z.; Foroutan-Nejad, C. Unification of ground-state aromaticity criteria - structure, electron delocalization, and energy - in light of the quantum chemical topology. Phys. Chem. Chem. Phys. 2016, 18, 11693-11699.

(9) von Ragué Schleyer, P.; Jiao, H. What is aromaticity? Pure Appl. Chem. 1996, 28, 209-218.

(10) Stanger, A. What is aromaticity: a critique of the concept of aromaticity-can it really be defined? Chem. Comm. 2009, 1939-1947.

(11) Jug, K.; Köster, A. Aromaticity as a Multi-Dimensional Phenomenon. J. Phys. Org. Chem. 1991, 4, 163-169.

(12) Neus, J. Aromatizität: Geschichte und mathematische Analyse eines fundamentalen chemischen Begriffs; HYLE Publications: Karlsruhe, 2002.

(13) Bird, C. W. The Relationship of Classical and Magnetic Criteria of Aromaticity. Tetrahedron 1996, 52, 9945-9952.

(14) Fowler, P. W.; Steiner, E.; Havenith, R. W. A.; Jenneskens, L. W. Current density, chemical shifts and aromaticity. Magn. Reson. Chem. 2004, 42, S68-S78.

(15) Aihara, J.-i. Circuit Resonance Energy: A Key Quantity That Links Energetic and Magnetic Criteria of Aromaticity. J. Am. Chem. Soc. 2006, 128, 2873-2879.

(16) Cyrañski, M. K.; Krygowski, T. M.; Katritzky, A. R.; von Ragué Schleyer, P. To What Extent Can Aromaticity Be Defined Uniquely?. J. Org. Chem. 2002, 67, 1333-1338. 
(17) Katritzky, A. R.; Barczyñski, P.; Musumarra, G.; Pisano, D.; Szafran, M. Aromaticity as a Quantitative Concept .1. A Statistical Demonstration of the Orthogonality of Classical and Magnetic Aromaticity in 5-Membered and 6-Membered Heterocycles. J. Am. Chem. Soc. 1989, 111, 7-15.

(18) Feixas, F.; Matito, E.; Poater, J.; Solá, M. On the performance of some aromaticity indices: A critical assessment using a test set. J. Comp. Chem. 2008, 29, 1543-1554.

(19) Krygowski, T. M.; Cyraski, M. K. Structural Aspects of Aromaticity. Chem. Rev. 2001, 101, 1385-1420.

(20) Kovacević, B.; Barić, D.; Maksić, Z. B.; Müller, T. The Origin of Aromaticity: Important Role of the Sigma Framework in Benzene. ChemPhysChem 2004, 5, 1352-1364.

(21) Fallah-Bagher-Shaidaei, H.; Wannere, C. S.; Corminboeuf, C.; Puchta, R.; von Ragué Schleyer, P. Which NICS aromaticity index for planar $\pi$ rings is best? Org. Lett. 2006, 8, 863-866.

(22) Fleischer, U.; Kutzelnigg, W.; Lazzeretti, P.; Muehlenkamp, V. IGLO Study of Benzene and Some of Its Isomers and Related Molecules. Search for Evidence of the Ring Current Model. J. Am. Chem. Soc. 1994, 116, 5298-5306.

(23) Pople, J. A.; Untch, K. G. Induced Paramagnetic Ring Currents. J. Am. Chem. Soc. 1966, $88,4811-4815$.

(24) McConnell, H. M. Theory of Nuclear Magnetic Shielding in Molecules. I. Long-Range Dipolar Shielding of Protons. J. Chem. Phys. 1957, 27, 226-229.

(25) Jusélius, J.; Patzschke, M.; Sundholm, D. Calculation of ring-current susceptibilities for potentially homoaromatic hydrocarbons. J. Mol. Struct. (Theochem) 2003, 633, $123-136$. 
(26) Wannere, C. S.; von Ragué Schleyer, P. How Do Ring Currents Affect ${ }^{1} \mathrm{H}$ NMR Chemical Shifts? Org. Lett. 2003, 5, 605-608.

(27) Valiev, R. R.; Fliegl, H.; Sundholm, D. New insights into magnetically induced current pathways and optical properties of isophlorins. J. Phys. Chem. A 2013, 117, 90629068.

(28) Pople, J. A. Molecular Orbital Theory of Aromatic Ring Currents. Mol. Phys. 1958, 1, 175-180.

(29) McWeeny, R. Ring Currents and Proton Magnetic Resonance in Aromatic Molecules. Mol. Phys. 1958, 1, 311-321.

(30) Gomes, J. A. N. F.; Mallion, R. B. Aromaticity and Ring Currents. Chem. Rev. 2001, 101, 1349-1384.

(31) Baldridge, K. K.; Gordon, M. S. Potentially aromatic metallocycles. J. Am. Chem. Soc. 1988, 110, 4204-4208.

(32) Nyulaszi, L.; Karpati, T.; Veszpremi, T. Silylene, the Most Stable Form of Silicon in Aromatic Compounds. J. Am. Chem. Soc. 1994, 116, 7239-7242.

(33) Glukhovtsev, M. N.; Bach, R. D.; Laiter, S. Isodesmic and homodesmotic stabilization energies of $[\mathrm{n}]$ annulenes and their relevance to aromaticity and antiaromaticity: is absolute antiaromaticity possible? J. Mol. Struct. (Theochem) 1997, 417, 123-129.

(34) Cyrański, M. K. Energetic Aspects of Cyclic Pi-Electron Delocalization: Evaluation of the Methods of Estimating Aromatic Stabilization Energies. Chem. Rev. 2005, 105, 3773-3811.

(35) Lazzeretti, P. Ring currents. Prog. Nucl. Magn. Reson. Spectrosc. 2000, 36, 1-88. 
(36) Sundholm, D.; Berger, R. J. F.; Fliegl, H. Analysis of the Magnetically Induced Current Density for Molecules Consisting of Annelated Aromatic and Antiaromatic Hydrocarbon Rings. Phys. Chem. Chem. Phys. 2016, 18, 15934-15942.

(37) Cao, J.; London, G.; Dumele, O.; von Wantoch Rekowski, M.; Trapp, N.; Ruhlmann, L.; Boudon, C.; Stanger, A.; Diederich, F. The Impact of Antiaromatic Subunits in [4n+2] $\pi$-Systems: Bispentalenes with [4n+2] $\pi$-Electron Perimeters and Antiaromatic Character. J. Am. Chem. Soc. 2015, 137, 7178-7188.

(38) Hernández-Lima, J. G.; Barquera-Lozada, J. E.; Cuevas, G.; Cortés-Guzmán, F. The Role of Induced Current Density in Steroelectronic Effects: Perlin Effect. J. Comp. Chem. 2015, 36, 1573-1578.

(39) Abersfelder, K.; White, A. J. P.; Berger, R. J. F.; Rzepa, H. S.; Scheschkewitz, D. A Stable Derivative of the Global Minimum on the $\mathrm{Si}_{6} \mathrm{H}_{6}$ Potential Energy Surface. Angew. Chem. Int. Ed. 2011, 50, 7936-7939.

(40) Zanasi, R.; Lazzeretti, P.; Malagoli, M.; Piccinini, F. Molecular magnetic properties within continuous transformations of origin of the current density. J. Chem. Phys. 1995, 102, 7150-7157.

(41) Jusélius, J.; Sundholm, D.; Gauss, J. Calculation of Current Densities using GaugeIncluding Atomic Orbitals. J. Chem. Phys. 2004, 121, 3952-3963.

(42) Fliegl, H.; Sundholm, D.; Taubert, S.; Jusélius, J.; Klopper, W. Magnetically Induced Current Densities in Aromatic, Antiaromatic, Homoaromatic, and Nonaromatic Hydrocarbons. J. Phys. Chem. A 2009, 113, 8668-8676.

(43) Taubert, S.; Sundholm, D.; Jusélius, J. Calculation of spin-current densities using gauge-including atomic orbitals. J. Chem. Phys. 2011, 134, 054123. 
(44) Fliegl, H.; Taubert, S.; Lehtonen, O.; Sundholm, D. The gauge including magnetically induced current method. Phys. Chem. Chem. Phys. 2011, 13, 20500-20518.

(45) Sundholm, D.; Fliegl, H.; Berger, R. J. Calculations of magnetically induced current densities: theory and applications. WIREs Comput. Mol. Sci. 2016, 6, 639-678.

(46) Aihara, J.-i. Magnetic resonance energy and topological resonance energy. Phys. Chem. Chem. Phys. 2016, 18, 11847-11857.

(47) Carion, R.; Champagne, B.; Monaco, G.; Zanasi, R.; Pelloni, S.; Lazzeretti, P. Ring Current Model and Anisotropic Magnetic Response of Cyclopropane. J. Chem. Theory Comput. 2010, 6, 2002-2018.

(48) Monaco, G.; Zanasi, R.; Pelloni, S.; Lazzeretti, P. Relative Weights of $\sigma$ and $\pi$ Ring Currents in a Few Simple Monocycles. J. Chem. Theory Comput. 2010, 6, 3343-3351.

(49) Badri, Z.; Pathak, S.; Fliegl, H.; Rashidi-Ranjbar, P.; Bast, R.; Marek, R.; ForoutanNejad, C.; Ruud, K. All-Metal Aromaticity: Revisiting the Ring Current Model among Transition Metal Clusters. J. Chem. Theory Comput. 2013, 9, 4789-4796.

(50) Pelloni, S.; Monaco, G.; Della Porta, P.; Zanasi, R.; Lazzeretti, P. Delocalized Currents without a Ring of Bonded Atoms: Strong Delocalized Electron Currents Induced by Magnetic Fields in Noncyclic Molecules. J. Phys. Chem. A 2014, 118, 3367-3375.

(51) Gershoni-Poranne, R.; Stanger, A. Magnetic criteria of aromaticity. Chem. Soc. Rev. 2015, 44, 6597-6615.

(52) von Ragué Schleyer, P.; Maerker, C.; Dransfeld, A.; Jiao, H.; van Eikema Hommes, N. J. R. Nucleus-Independent Chemical Shifts: A Simple and Efficient Aromaticity Probe. J. Am. Chem. Soc. 1996, 118, 6317-6318. 
(53) Zhao, L.; Grande-Aztatzi, R.; Foroutan-Nejad, C.; Ugalde, J. M.; Frenking, G. Aromaticity, the Hückel 4n+2 Rule and Magnetic Current. ChemistrySelect 2017, 2, $863-870$.

(54) Giambiagi, M.; de Giambiagi, M. S.; dos Santos Silva, C. D.; de Figueiredo, A. P. Multicenter bond indices as a measure of aromaticity. Phys. Chem. Chem. Phys. 2000, 2, 3381-3392.

(55) Cioslowski, J.; Matito, E.; Sol, M. Properties of Aromaticity Indices Based on the One-Electron Density Matrix. J. Phys. Chem. A 2007, 111, 6521-6525.

(56) Islas, R.; Martínez-Guajardo, G.; Jiménez-Halla, J. O. C.; Solá, M.; Merino, G. Not All That Has a Negative NICS Is Aromatic: The Case of the H-Bonded Cyclic Trimer of HF. J. Chem. Theory Comput. 2010, 6, 1131-1135.

(57) Lin, Y. C.; Sundholm, D.; Jusélius, J. On the Aromaticity of the Planar Hydrogen Bonded (HF) $)_{3}$ Trimer. J. Chem. Theory Comput. 2006, 2, 761-764.

(58) Jusélius, J.; Sundholm, D. Ab initio determination of the induced ring current in aromatic molecules. Phys. Chem. Chem. Phys. 1999, 1, 3429-3435.

(59) Lazzeretti, P. Assessment of aromaticity via molecular response properties. Phys. Chem. Chem. Phys. 2004, 6, 217-223.

(60) Pelloni, S.; Monaco, G.; Lazzeretti, P.; Zanasi, R. Beyond NICS: estimation of the magnetotropicity of inorganic unsaturated planar rings. Phys. Chem. Chem. Phys. 2011, 13, 20666-20672.

(61) Morao, I.; Lecea, B.; Cossío, F. P. In-Plane Aromaticity in 1,3-Dipolar Cycloadditions. J. Org. Chem. 1997, 62, 7033-7036. 
(62) Jiménez-Halla, J. O. C.; Matito, E.; Robles, J.; Solá, M. Nucleus-independent chemical shift (NICS) profiles in a series of monocyclic planar inorganic compounds. $J$. Organomet. Chem. 2006, 691, 4359-4366.

(63) Pelloni, S.; Lazzeretti, P. Polygonal Current Model: An Effective Quantifier of Aromaticity on the Magnetic Criterion. J. Phys. Chem. A 2013, 117, 9083-9092.

(64) Monaco, G.; Zanasi, R. Assessment of Ring Current Models for Monocycles. J. Phys. Chem. A 2014, 118, 1673-1683.

(65) Du, D.; Fliegl, H.; Sundholm, D. Evaluating Shielding-Based Ring-Current Models by Using the Gauge-Including Magnetically Induced Current Method. J. Chin. Chem. Soc. 2016, 63, 93-100.

(66) Van Damme, S.; Acke, G.; Havenith, R. W. A.; Bultinck, P. Can the current density map topology be extracted from the nucleus independent chemical shifts? Phys. Chem. Chem. Phys. 2016, 18, 11746-11755.

(67) Mucsi, Z.; Viskolcz, B.; Csizmadia, I. G. A Quantitative Scale for the Degree of Aromaticity and Antiaromaticity: A Comparison of Theoretical and Experimental Enthalpies of Hydrogenation. J. Phys. Chem. A 2007, 111, 1123-1132.

(68) Becke, A. D. Density-functional thermochemistry. III. The role of exact exchange. J. Chem. Phys. 1993, 98, 5648-5652.

(69) Lee, C.; Yang, W.; Parr, R. G. Development of the Colle-Salvetti correlation-energy formula into a functional of the electron density. Phys. Rev. B 1988, 37, 785-789.

(70) Frisch, M. J.; Trucks, G. W.; Schlegel, H. B.; Scuseria, G. E.; Robb, M. A.; Cheeseman, J. R.; Scalmani, G.; Barone, V.; Mennucci, B.; Petersson, G. A. et al. Gaussian 09 Revision E.01. Gaussian Inc. Wallingford CT 2009. 
(71) Hehre, W. J.; Ditchfield, R.; Pople, J. A. Self-Consistent Molecular Orbital Methods. XII. Further Extensions of Gaussian-Type Basis Sets for Use in Molecular Orbital Studies of Organic Molecules. J. Chem. Phys. 1972, 56, 2257-2261.

(72) Humphrey, W.; Dalke, A.; Schulten, K. VMD: Visual molecular dynamics. J. Mol. Graphics 1996, 14, 33-38.

(73) Schäfer, A.; Huber, C.; Ahlrichs, R. Fully Optimized Contracted Gaussian-Basis Sets of Triple Zeta Valence Quality for Atoms Li to Kr. J. Chem. Phys. 1994, 100, 58295835.

(74) Weigend, F.; Ahlrichs, R. Balanced basis sets of split valence, triple zeta valence and quadruple zeta valence quality for H to Rn: Design and assessment of accuracy. Phys. Chem. Chem. Phys. 2005, 7, 3297-3305.

(75) Häser, M.; Ahlrichs, R.; Baron, H. P.; Weis, P.; Horn, H. Direct computation of 2ndorder SCF properties of large molecules on workstation computers with an application to large carbon clusters. Theoret. Chim. Acta 1992, 83, 455-470.

(76) Ahlrichs, R.; Bär, M.; Häser, M.; Horn, H.; Kölmel, C. Electronic Structure Calculations on Workstation Computers: The Program System TURBOMOLE. Chem. Phys. Letters 1989, 162, 165-169, current version: see http://www.turbomole.com.

(77) Furche, F.; Ahlrichs, R.; Hättig, C.; Klopper, W.; Sierka, M.; Weigend, F. Turbomole. WIREs Comput. Mol. Sci. 2014, 4, 91-100.

(78) Kollwitz, M.; Gauss, J. A direct implementation of the GIAO-MBPT(2) method for calculating NMR chemical shifts. Application to the naphthalenium and anthracenium ions. Chem. Phys. Letters 1996, 260, 639-646.

(79) Kollwitz, M.; Häser, M.; Gauss, J. Non-Abelian point group symmetry in direct 
second-order many-body perturbation theory calculations of NMR chemical shifts. J. Chem. Phys. 1998, 108, 8295-8301.

(80) GIMIC, version 2.0, a current density program. Can be freely downloaded from https://github.com/qmcurrents/gimic.

(81) Sulzer, D.; Olejnicaz, M.; Bast, R.; Saue, T. 4-component relativistic mangetically induced current density using London atomic orbitals. Phys. Chem. Chem. Phys. 2011, $x x x, \mathrm{xxx}-\mathrm{xxx}$.

(82) Pathak, S.; Bast, R.; Ruud, K. Multiconfigurational Self-Consistent Field Calculations of the Magnetically Induced Current Density Using Gauge-Including Atomic Orbitals. J. Chem. Theory Comput. 2013, 9, 2189-2198.

(83) Komorovsky, S.; Repisky, M.; Malkina, O. L.; Malkin, V. G. Fully relativistic calculations of NMR shielding tensors using restricted magnetically balanced basis and gauge including atomic orbitalsa). J. Chem. Phys. 2010, 132, 154101.

(84) Lazzeretti, P.; Malagoli, M.; Zanasi, R. Computational Approach to Molecular Magnetic-Properties by Continuous Transformation of the Origin of the CurrentDensity. Chem. Phys. Letters 1994, 220, 299-304.

(85) Coriani, S.; Lazzeretti, P.; Malagoli, M.; Zanasi, On CHF calculations of second-order magnetic properties using the method of continuous transformation of origin of the current density. Theoret. Chim. Acta 1994, 89, 181-192.

(86) Tellgren, E. I.; Soncini, A.; Helgaker, T. Nonperturbative ab initio calculations in strong magnetic fields using London orbitals. J. Chem. Phys. 2008, 129, 154114.

(87) Tellgren, E. I.; Teale, A. M.; Furness, J. W.; Lange, K. K.; Ekström, U.; Helgaker, T. Non-perturbative calculation of molecular magnetic properties within current-density functional theory. J. Chem. Phys. 2014, 140, 034101. 
(88) Chen, Z.; Wannere, C. S.; Corminboeuf, C.; Puchta, R.; von Ragué Schleyer, P. Nucleus-Independent Chemical Shifts (NICS) as an Aromaticity Criterion. Chem. Rev. 2005, 105, 3842-3888.

(89) Gershoni-Poranne, R.; Stanger, A. The NICS-XY-Scan: Identification of Local and Global Ring Currents in Multi-Ring Systems. Chem. Eur. J. 2014, 20, 5673-5688.

(90) Fliegl, H.; Jusélius, J.; Sundholm, D. Gauge-Origin Independent Calculations of the Anisotropy of the Magnetically Induced Current Densities. J. Phys. Chem. A 2016, $120,5658-5664$.

(91) Horner, K. E.; Karadakov, P. B. Chemical Bonding and Aromaticity in Furan, Pyrrole, and Thiophene: A Magnetic Shielding Study. J. Org. Chem. 2013, 78, 8037-8043.

(92) Poater, J.; Solá, M.; Viglione, R. G.; Zanasi, R. Local Aromaticity of the SixMembered Rings in Pyracylene. A Difficult Case for the NICS Indicator of Aromaticity. J. Org. Chem. 2004, 69, 7537-7542.

(93) Jusélius, J.; Sundholm, D. Polycyclic Antiaromatic Hydrocarbon. Phys. Chem. Chem. Phys. 2008, 10, 6630-6634.

(94) Johansson, M. P.; Jusélius, J.; Sundholm, D. Sphere Currents of Buckminsterfullerene. Angew. Chem. Int. Ed. 2005, 44, 1843-1846.

(95) Taubert, S.; Jusélius, J.; Sundholm, D.; Klopper, W.; Fliegl, H. Calculation of magnetically induced currents in hydrocarbon nanorings. J. Phys. Chem. A 2008, 112, 13584-13592.

(96) Taubert, S.; Sundholm, D.; Pichierri, F. Magnetically Induced Currents in Bianthraquinodimethane-Stabilized Möbius and Hückel [16]Annulenes. J. Org. Chem. 2009, 74, 6495-6502. 
(97) Fliegl, H.; Sundholm, D.; Pichierri, F. Aromatic Pathways in Mono- and Bisphosphorous Singly Möbius Twisted [28] and [30]Hexaphyrins. Phys. Chem. Chem. Phys. 2011, 13, 20659-20665.

(98) Fliegl, H.; Özcan, N.; Mera-Adasme, R.; Pichierri, F.; Jusélius, J.; Sundholm, D. Aromatic pathways in thieno-bridged porphyrins: understanding the influence of the direction of the thiophene ring on the aromatic character. Mol. Phys. 2013, 111, 1364-1372.

(99) Sundholm, D. $\mathrm{C}_{72}$ : Gaudiene a Hollow and Aromatic All-Carbon Molecule. Phys. Chem. Chem. Phys. 2013, 15, 9025-9028.

(100) Valiev, R. R.; Fliegl, H.; Sundholm, D. Aromatic Pathways in Carbathiaporphyrins. J. Phys. Chem. A 2015, 119, 1201-1207.

(101) Valiev, R. R.; Fliegl, H.; Sundholm, D. The aromatic character of thienopyrrole-

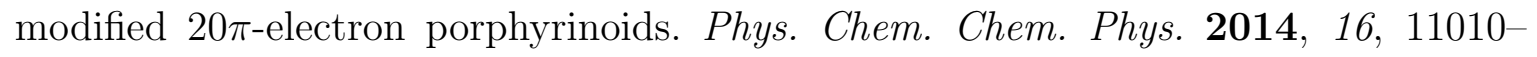
11016.

(102) Fliegl, H.; Pichierri, F.; Sundholm, D. Antiaromatic Character of $16 \pi$ Electron Octaethylporphyrins: Magnetically Induced Ring Currents from DFT-GIMIC Calculations. J. Phys. Chem. A 2015, 119, 2344-2350.

\section{Supporting Information Available}

Electronic supplementary information (ESI) available: Electronic energies, standard deviations of the fitting coefficients, and plots of the GIMIC fits are given in the supporting information. The Cartesian coordinates and isotropic NMR shielding constants of the investigated molecules are also reported as supporting information.

This material is available free of charge via the Internet at http://pubs.acs.org/. 


\section{Graphical TOC Entry}

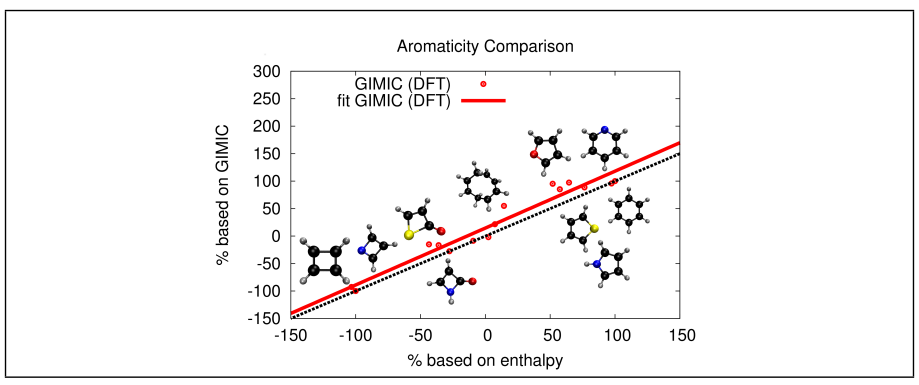

